\title{
ALLIANCE CAPABILITY, STOCK MARKET RESPONSE, AND LONG-TERM ALLIANCE SUCCESS: THE ROLE \author{
OF THE ALLIANCE FUNCTION \\ PRASHANT KALE, ${ }^{1 *}$ JEFFREY H. DYER ${ }^{2}$ AND HARBIR SINGH ${ }^{3}$ \\ 1 University of Michigan Business School, Ann Arbor, Michigan, U.S.A. \\ ${ }^{2}$ Marriott School of Management, Brigham Young University, Provo, Utah, U.S.A. \\ ${ }^{3}$ The Wharton School of Business, University of Pennsylvania, Philadelphia, \\ Pennsylvania, U.S.A.
}

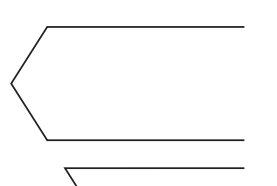

\begin{abstract}
This paper addresses two key questions: (1) what factors influence firms' ability to build alliance capability and enjoy greater alliance success, where firm-level alliance success is measured in two ways: (a) abnormal stock market gains following alliance announcements and (b) managerial assessments of long term alliance performance; and (2) are the two alternate ways of assessing alliance success correlated? We find that firms with greater alliance experience and, more importantly, those that create a dedicated alliance function (with the intent of strategically coordinating alliance activity and capturing/disseminating alliance-related knowledge) realize greater success with alliances. More specifically, firms with a dedicated alliance function achieve greater abnormal stock market gains (average of 1.35\%) and report that 63 percent of alliances are successful whereas firms without an alliance function achieve much lower stock market gains (average of $0.18 \%$ ) and only a 50 percent long-term success rate. We also find a positive correlation between stock market-based measures of alliance success and alliance success measured through managerial assessments. In addition to providing insights into the development of alliance capability among firms, this paper is one of the first to provide empirical support for the efficient markets argument by demonstrating that the initial stock market response to a key event positively correlates to the long-term performance and value of the event. Copyright (c) 2002 John Wiley \& Sons, Ltd.
\end{abstract}

\section{INTRODUCTION}

During the past two decades alliances have become one of the most important organizational forms, as evidenced by the fact that more than 20,000 alliances have been reported in just the last 2 years (Anand and Khanna, 2000). The idea that alliances are an important vehicle for value creation is supported by studies suggesting that, on average, alliances do create economic value (Chan et al., 1997; Anand and Khanna, 2000). However, while alliances can create value, most studies find that roughly half the alliances formed end up failing (Kogut, 1989; Bleeke and Ernst, 1993; Alliance

Key words: alliances; capabilities; alliance success; efficient markets hypothesis

*Correspondence to: P. Kale, University of Michigan Business School, 701 Tappan Street, Ann Arbor, MI 48109-1234, U.S.A.
Analyst, 1998). Thus, while alliances can create economic value, they are also fraught with risk. This raises the question of how firms can, and should, manage alliances to maximize the probability of success.

Previous research on alliances suggests that perhaps the most important factor in alliance success is previous alliance experience (Anand and Khanna, 2000). The implicit assumption behind the relationship between alliance experience and success is that there are learning effects that enable firms to develop a 'relational capability' (Dyer and Singh, 1998). Indeed, there is ample anecdotal and case evidence suggesting that some firms, on the basis of repeated experience in managing certain organizational forms, have developed superior capabilities at managing them. For example, Hansen Trust and General Electric have been 
described as being particularly effective at managing acquisitions and multiple unrelated businesses (Allen, 1998; Baldwin and Forsyth, 1992). Thermo Electron is known to be effective at managing spin-offs, while Xerox has been described as a firm that is ineffective at managing spinoffs (Smith and Alexander, 1988). In the area of alliances, Hewlett-Packard, Corning, and CocaCola have been described as firms that have been successful at developing and managing alliances (Alliance Analyst, 1996; Harbison and Pekar, 1998; Kale and Singh, 1999). Given firm heterogeneity and differences in prior alliance experience, we would expect that some firms develop superior capabilities at managing particular organizational forms such as alliances. In support of this argument, Anand and Khanna (2000) found that firms with greater prior alliance experience generate significantly higher stock market returns from alliance announcements than firms with lesser alliance experience. Anecdotal data and case-based research also offer support for the argument that some firms learn how to develop and manage alliances better than others (Alliance Analyst, 1996; Dyer, 1996). However, detailed studies of what exactly constitutes an alliance capability are virtually nonexistent (Gulati, 1998). While we know that alliance experience is important, we still lack knowledge with regard to what is involved in developing an alliance capability. What do firms with alliance experience learn to do that allows them to achieve greater success in future alliances?

The purpose of this study is to examine the development of a firm-level alliance capability and to assess whether or not this capability is correlated with superior alliance performance. More specifically, we examine whether or not firms that invest in creating a dedicated alliance function (with the intent of strategically coordinating alliance activity and capturing alliance-related knowledge) enjoy greater alliance success as measured by both (a) greater stock market returns following alliance announcements and (b) managerial assessments of alliance performance. We also attempt to do something that has not been reported in prior research-we examine whether or not there is a strong correlation between stock market response to an alliance announcement and the long-term success of the alliance as perceived by the participants in the alliance. In other words, does the market do a good job at predicting which alliances will, over the long term, be successful at creating value for the participating firms?

We first develop our conceptual arguments based on a review of relevant academic literature. Extensive fieldwork with approximately 10 companies then preceded the large sample empirical study reported here. The fieldwork provided us rich insights on specific practices being followed by companies to build their alliance capability. We refer selectively to some of the comments from managers interviewed during fieldwork. We base our conclusions on our empirical study of 78 firms and their 1572 alliances.

\section{THEORY AND HYPOTHESES}

Interfirm alliances have become commonplace as firms attempt to access or absorb the capabilities of other firms. We define an alliance as any independently initiated interfirm link that involves exchange, sharing or co-development (see Gulati, 1995). This encompasses joint ventures, R\&D or production agreements, marketing or distribution agreements, or technology exchange.

Although alliances have become a popular organizational form for accessing resources, they frequently fail to live up to expectations. Studies by Harrigan (1985), Kogut (1989), and Anderson Consulting (Alliance Analyst, 1998) report failure rates of 50 percent, 54 percent and 53 percent respectively. Taken together, these studies indicate that alliance success is difficult to achieve. Thus, understanding what firms can do to enhance the probability of success is an intriguing and important question for both managers and alliance researchers.

Previous research suggests that alliance outcome and failure can be attributed to a number of factors, including: lack of strategic fit in terms of complementary resources (Harrigan, 1985), lack of organizational fit in terms of compatible cultures, decision-making processes, and systems (Kale, Singh, and Perlmutter, 2000), lack of trust (Arino and De la Torre, 1998), inappropriate choice of governance structure (Williamson, 1985; Hennart, 1988), inability to manage conflict (Doz and Hamel, 1998), lack of adaptable interorganizational exchange processes (Zajac and Olsen, 1993), impact of sudden major environmental shocks (Mitchell and Singh, 1996), etc. There is also some evidence that alliance failure is often 
tied to a lack of experience on the part of the firm with respect to forming and managing alliances. In fact, previous research suggests that one of the most important determinants of alliance success (and on a firm's ability to form new alliances) is prior and/or ongoing alliance experience (Fiol and Lyles, 1985; Child and Yan, 1999). Simonin (1997) found that greater alliance experience is linked with firms' abilities to effectively select alliance partners, manage alliance conflicts, etc. More recently, Anand and Khanna (2000) found that firms with greater prior alliance experience generate significantly higher stock market returns from alliance announcements than firms without alliance experience. They claim that 'firms learn to create more value as they accumulate experience in joint venturing.' Even in the context of the same set of partners, some studies suggest that prior experience of allying with the same partner helps the partnering companies in future alliances. Presumably, prior experience of this kind increases the success of future alliances with the same partner for several reasons. One, the firm in question may have greater commitment to make the alliance work given the trust among partners and, two, prior experience helps the firms build partner-specific routines of coordinating resources and tasks successfully with the partner. Overall, although many of these studies suggest 'prior experience matters,' they are basically silent with regard to how prior experience translates into a capability.

\section{ALLIANCE CAPABILITY AND ALLIANCE SUCCESS}

A number of theoretical perspectives offer insights into the issue of how firms might develop organizational capabilities. These primarily include perspectives from the resource-based view (Wernerfelt, 1984; Barney, 1991), dynamic capabilities (Teece, Pisano, and Shuen, 1997), evolutionary economics (Nelson and Winter, 1982), and the emerging literature on organizational learning and the knowledge-based view of the firm (Kogut and Zander, 1992, 1995; Conner and Prahalad, 1996; Grant, 1996). We believe that the organizational learning, dynamic capabilities, and evolutionary economics literatures offer some of the most useful insights with regard to capability development, since capabilities often rest upon unique sources of knowledge. A central theme of the recently coined 'knowledge-based view' is that individually and organizationally held knowledge acts as a basis for creating firm-level capabilities that act as a source of competitive advantage (Grant, 1996). Organizational capabilities develop as a result of recombining and/or integrating knowledge within the firm. This knowledge is typically built through learning that involves making associations between a firm's past actions, the effectiveness of those actions, and future actions (Fiol and Lyles, 1985). In effect, capabilities are developed through a process that involves the interpretation of past individual and organizational experience as a basis for present and future action. Firms will likely be more effective at capability development when they develop mechanisms or routines that are purposefully designed to accumulate, store, integrate, and diffuse relevant organizational knowledge acquired through individual and organizational experience. Routines have been defined by Nelson and Winter (1982) as the stable and predictable patterns of quasi-automatic behavior developed and constantly refined at the margin by firms in the course of their ordinary productive activities.

Expanding on the core ideas in evolutionary economics, Zollo (1998) and Kale and Singh (1999) argue that firm capabilities are developed on the basis of incremental learning and finetuning of relevant day-to-day activities in the firm. Other researchers have suggested that organizational capabilities could also develop by replacing or supplementing such incremental learning by higher-order learning activities or organizing principles through which individual and group knowledge is structured and coordinated within the firm. Prior researchers have referred to these organizing principles as the firm's 'combinative capabilities' (Zander and Kogut, 1995) or 'architectural competence' (Henderson and Cockburn, 1994). ${ }^{1}$ Essentially, they comprise organizational processes that are used to integrate and coordinate knowledge and activities across various people and subunits within the firm. These integrative mechanisms act as an important locus of firm learning, by enabling generation and facilitation of feedback from prior and ongoing experiments and experiences in various parts of the firm (Pisano, 1994). Grant (1996) has

\footnotetext{
${ }^{1}$ Architectural competence or learning refers to the development of new ways of recombining existing routines (and knowledge) within the firm.
} 
recommended the use of hierarchical structures, teams, and rules and directives for this purpose.

Henderson and Cockburn (1994) have demonstrated the usefulness of higher-order organizing mechanisms to coordinate R\&D know-how and activities within pharmaceutical firms. They refer to such mechanisms as the firm's architectural competence with respect to $\mathrm{R} \& \mathrm{D}$, and they operationalize it in terms of the extent to which research activities are coordinated as a seamless whole and managed centrally by a focal individual or team. They find that having a team or individual that centrally coordinates the firm's R\&D know-how and activity leads to significant improvements in R\&D productivity. Similarly, Clark and Fujimoto (1990) have highlighted the positive impact of centrally coordinating various groups and activities during the development of new product designs in the automotive industry. Their research shows that having such a mechanism ('heavyweight teams') leads to a significant reduction in the time and cost associated with developing new product designs. Finally, Dyer and Nobeoka (2000) examine the issue of how Toyota and its suppliers learn faster (show greater productivity improvements) than competitors. They claim that one important factor in explaining Toyota's relative learning capability is that Toyota has created a separate organizational unit that has been assigned the responsibility to accumulate, store, integrate, and diffuse production knowledge. Toyota's 'Operations Management Consulting Division' represents a mechanism designed to centrally coordinate and share valuable production knowledge throughout Toyota's network.

We, along with some other scholars (Harbison and Pekar, 1998; Mitchell, 2000; Reuer, 2000), believe that centralized coordination of this kind is becoming equally important in the alliance context. Thus, while greater firm alliance experience may be a necessary and important condition for firms to build alliance capability, it may not be sufficient. Experience is but a crude approximation of the mechanisms that lie at the foundation of building alliance capability. Alliance capability would rest upon how effectively the firm is able to capture, share, and disseminate the alliance management know-how associated with prior experience. To the extent that firms engage in these activities in the form of a fairly stable and repetitive pattern, these activities can be viewed as the knowledge management routines that form the basis for an alliance capability.

Our research suggests that one important way that organizations can capture, integrate, and disseminate alliance-management know-how is through the creation of a separate, dedicated organizational unit charged with the responsibility to capture prior experience. We refer to this as a 'dedicated alliance function.' For example, firms such as Hewlett Packard, Eli Lilly, and ParkeDavis have appointed a 'Vice President or Director of Strategic Alliances' with his/her own staff and resources. This dedicated function coordinates all alliance-related activity within the firm and can enhance the firm's ability to generate high returns from alliances in a number of ways.

First, a dedicated function can act as a focal point for learning and leveraging lessons from prior and ongoing alliances. It can facilitate a more systematic and routine implementation of processes to codify (Zollo, 1998), learn, and leverage alliance know-how. Our fieldwork indicates that many companies with dedicated alliance functions have attempted to codify alliance-management knowledge by creating guidelines and manuals to help their managers handle specific aspects of the alliance life cycle better, such as partner selection, alliance negotiation, formulation of alliance contracts, alliance termination, etc. For example, Lotus Corporation has created ' 35 rules of thumb' to manage each phase of an alliance, from formation through termination. Hewlett-Packard has developed 60 different tools and templates included in a 300-page manual that can be used to guide action or decision making in specific alliance situations (Kale and Singh, 1999). Other firms such as Xerox, Smithkline Beecham, and Oracle have followed a similar approach. These actions are purposefully designed to codify and share relevant alliance know-how to enhance the probability of alliance success.

A dedicated alliance function can also increase the firm's tacit knowledge with regard to alliance management. Individuals who are assigned to work in this function are in a position to develop significant firsthand experience with regard to every facet of an alliance, from formation to termination. Moreover, a dedicated alliance function can facilitate the sharing of tacit knowledge through training programs and by creating internal networks of alliance managers. For example, HP has developed a 2-day course on alliance 
management that is offered three times a year. It also creates opportunities for internal networking among its managers through its internal training programs, company-wide alliance summits, and 'virtual meetings' with executives involved in managing alliances. The company also regularly sends its alliance managers to alliance management programs conducted by various business schools. These programs often help them develop their external network of alliance contacts. Besides playing an important role in building the alliance know-how of its managers as described above, a dedicated alliance function also acts as a repository for all the alliance know-how within the company. Alliance knowledge that resides experientially with individual managers is likely to dissipate over time in the face of natural turnover among them. By codifying this know-how and by absorbing it, the alliance function plays an important role in retaining the knowledge that otherwise might be lost if managers that possess it were to leave the organization.

Second, a dedicated alliance function can play an important role in keeping the market apprised of both new alliances and successful events in ongoing alliances. Such external visibility can enhance the reputation of the company in the marketplace and create the perception that alliances are adding value. Moreover, when a potential partner wants to contact a company about a potential alliance, a dedicated alliance function makes an easy, highly visible point of contact. In essence, it provides a place to screen potential partners and bring in the appropriate internal parties if a partnership looks attractive. As a VP of alliances in a pharmaceutical company stated, 'Having a dedicated group focused on alliances has definitely made a difference. A dedicated alliance function helps us to be more visible in the alliance arena. Right now I get two to three unsolicited calls per day from firms who are interested in alliances. We act as a clearinghouse and screen them to see if there is a good fit and if they have a good internal infrastructure to support alliances.'

Third, in our interviews some executives indicated that one reason that alliances fail is because of the inability of one partner or another to mobilize internal resources to support the alliance initiative. Visionary alliance leaders may lack the power or organizational authority to access key resources that may be necessary to ensure alliance success. A dedicated strategic alliance function often has the legitimacy required to access and coordinate internal resources across different functions and divisions. An alliance executive at a firm without such a function observed:

\begin{abstract}
We have a difficult time in supporting our alliance initiatives because many times the various resources and skills needed to support a particular alliance are located in different functions around the company. Unless it is a very high-profile alliance, no one person has the power to make sure the company's full resources are utilized to help the alliance succeed. You have to go begging to each unit and hope that they will support you. But that's time consuming and we don't always get the support we should.
\end{abstract}

A dedicated alliance function helps solve this problem in two ways. First, it has the organizational legitimacy to reach across divisions and functions and request the resources necessary to support the firm's alliance initiatives. When particular functions are not responsive, it can quickly elevate the issue through the organization's hierarchy and request the appropriate executives to make a decision on whether a particular function or division should support an alliance initiative. Second, over time, individuals within the alliance function develop networks of contacts throughout the organization. They come to know where various useful resources reside within the organization. These networks also develop some trust between alliance managers and employees in the organization, thereby facilitating reciprocal exchanges in support of alliance initiatives.

Finally, many executives we interviewed indicated that an important benefit of creating an alliance function was that it motivated the company to develop alliance metrics and to systematically evaluate the performance of its alliances. Developing such evaluation processes compelled senior managers to intervene when an alliance was struggling. For example, Eli Lilly does a "health check' on each of its key alliances at least once a year, surveying both Lilly alliance managers and the partner's alliance managers. After the survey, an alliance manager from the dedicated function sits down with the leader of a particular alliance to discuss the results and offer suggestions or recommendations. In some cases, Lilly found that it needed to replace its alliance leader. When serious conflicts arise, the alliance function can act as a facilitator to help resolve the dispute. As an alliance executive in a software company noted, 
'After setting up our alliance team, we conduct regular partner assessments during the alliance to see if the alliance is working. If it's not, we step in to help resolve any conflicts and get the alliance back on track.' (Interview, 2 December 1998)

In summary, an investment in a dedicated alliance function can enhance a firm's alliance capability by: (1) acting as a focal point for learning and leveraging both explicit and tacit lessons from prior and ongoing alliances; (2) keeping numerous stakeholders, including investors, apprised of new alliances and successful events in ongoing alliances; (3) improving internal coordination and resource support of alliances; and (4) monitoring and evaluating alliance performance. All these activities should help the firm in generating greater value and success with its alliances. Such value in alliances may often get reflected in abnormal stock gains for the firm in question following the formation of its alliances. The excess returns reflect the expected value that the market believes the firm will capture by entering into the particular alliance. The existence of alliance capability due to the dedicated alliance function and its specific role described above may be useful in generating a positive stock market response to an alliance announcement. Thus, we hypothesize as follows:

Hypothesis 1: Strategic alliance announcements from firms that have made an investment in a dedicated strategic alliance function will result in higher abnormal stock market returns than announcements from firms without a dedicated strategic alliance function.

Of course, if the dedicated alliance function is truly effective as a central coordination mechanism that improves the firm's overall capability at managing alliances, the firm should also achieve greater longterm success with its portfolio of alliances.

Hypothesis 2: There is a positive relationship between a firm's investment in a dedicated strategic alliance function and its overall longterm success with alliances.

\section{ALLIANCE EXPERIENCE AND A DEDICATED ALLIANCE FUNCTION}

From a practical standpoint, companies that form only a few alliances may find it relatively easy to manage their alliance portfolio. When a firm has only a few alliances it is easier for its managers to understand how each alliance fits with the firm's strategic objectives, as well as how it relates to other alliances. However, as the number of alliances that a firm must manage simultaneously increases, it may be very difficult for the company's management to manage and monitor the performance of its alliances, understand whether there is potential conflict or overlap between different alliances, or between partners of different alliances, etc. Under these circumstances, companies may adopt a more coordinated approach to managing their alliance portfolio. This is especially true of companies in industries like computers or telecommunications, where each company ends up allying strategically with multiple partners, many of whom are fierce rivals or closer compatriots.

Further, as strategic alliances become more important as an organizational form for accessing resources, they become vital to a firm's overall performance. Thus, firms have greater incentives to manage them effectively. Thus, we expect that as a company accumulates a larger portfolio of alliances (i.e., by accumulating a large portfolio of alliances we mean not only many alliances over time but also a greater number of alliances that the firm must manage simultaneously), ceteris paribus it would be more likely to invest in a dedicated alliance function to manage its alliance portfolio. Thus, we hypothesize as follows:

\section{Hypothesis 3: The greater the firm's cumulative number of alliances, the more likely the firm will establish a dedicated alliance function to coordinate and manage its alliance activity.}

It is perhaps possible that once firms invest in an alliance function they are likely to initiate more alliances in the future because they now have devoted focused resources to actively search for alliance opportunities and provide rapid assistance to form and implement them.

\section{ALLIANCE ANNOUNCEMENTS AND LONG-TERM ALLIANCE SUCCESS}

Research on alliance performance has been difficult to conduct due to research obstacles that include measuring alliance performance in a consistent and appropriate manner, and the logistical 
challenges of collecting the rich data necessary to assess performance (Gulati, 1998). With the exception of joint ventures, which are separate legal entities, it has been very difficult to measure alliance performance using traditional accounting or financial measures like sales growth, return on assets, or profitability. Consequently, some researchers have used stability or longevity as a measure of performance. However, these measures of alliance performance have attracted criticism for their limited ability to provide information about collaboration effectiveness (Kogut, 1989). Measures such as survival and longevity fail to distinguish between alliances that fail and therefore die, and those that accomplish their objectives and thus outlive their utility.

Alliance performance has also been studied using managerial assessments of performance. Managers assess performance in terms of their overall satisfaction with the alliance, or in terms of the extent to which an alliance has met its stated objectives (Anderson and Narus, 1990; Beamish, 1984; Hebert and Beamish, 1997; Mohr and Spekman, 1994; Parkhe, 1993; Saxton, 1997). Managerial assessments of alliance performance received some initial criticism for reasons of bias and inaccuracy. This was especially true until research by Geringer and Hebert (1991) demonstrated the existence of a high correlation between subjective assessments of performance with more objective measures, based on accounting data. Thus, there is an emerging consensus among scholars that, if properly done, managerial assessments are a reasonable way to assess alliance performance (Anderson and Weitz, 1989; Anderson, 1990; Child and Yan, 1999; Das and Teng, 2000).

More recently, the event study methodology has also been used to assess alliance success and the economic value created by alliances (Koh and Venkatraman, 1991; Chan et al., 1997; McConnell and Nantel, 1985; Anand and Khanna, 2000). This methodology, which has been widely used to assess the performance of acquisitions, explicitly relies on the assumption that the market is efficient, meaning that the market has enough information to accurately assess the impact of a major strategic event, such as an acquisition or alliance. However, some researchers have criticized this methodology arguing that the market is, at best, semi-strong form efficient and that initial responses to strategic events could be very inaccurate. Indeed, there are examples of acquisitions or alliances to which the market responded positively but that ended up in failure.

To date, there are no studies that we are aware of that have attempted to explicitly test whether or not the initial stock market gains following an acquisition or alliance is related to the long-term benefits realized by the firm, as measured by either accounting measures or managerial assessments. Are alliances that produce a higher stock market response more likely to create value for the firm (over the long term) in the ways envisioned at the time of the announcement? We test the argument that the market is efficient by examining whether or not there is a positive relationship between ex ante market expectations of alliance success and the long-term success of the alliance. We do not state this as a formal hypothesis because it follows directly from the efficient markets hypothesis.

\section{RESEARCH DESIGN AND METHODOLOGY}

We first conducted exploratory fieldwork to understand the role of alliance experience and a dedicated alliance function in driving alliance capability and success. This fieldwork was useful in helping us develop the theoretical arguments and relationships proposed earlier. We next collected large-sample data to test and validate some of the key relationships proposed here.

The level of analysis in our study is the firm. Given our research questions, it was necessary to collect data from those firms that actually engaged in alliances and that operated in industries where alliances are generally considered an important element of firm strategy. We identified computers, telecommunications, pharmaceuticals, chemicals, electronics, and services as a sample of industries that fall within this category (Culpan and Eugene, 1993; Alliance Analyst, 1996). We selected our sample of companies within those industries by identifying all firms in each industry with more than $\$ 500$ million annual sales for the year 1997 (industry categories were identified on the basis of SIC codes; e.g., SIC Code 283 for pharmaceuticals, 357 for computer hardware, etc.).

For the companies in this set, we first collected contact information on a senior executive who might be in charge of or involved in the firm's alliance activities (we used the S\&P digest 
on company executives and Lexus-Nexus, etc.). These executives were typically in corporate development, business development or, in some cases, were identified as a director or vice-president of strategic alliances. We then contacted each company in our initial pool to validate the above information. Using this process we were able to identify a key informant in 292 companies in the original set. This person was the primary respondent for our study and provided us with data regarding the firm's alliance experience and its dedicated alliance function, if the company had created one. The primary respondent also assisted us in identifying appropriate managers in his/her company who were directly involved with each specific alliance formed by the company during 1993-97. The latter group of managers would act as secondary respondents and provide us with a performance assessment of their specific alliance. We used separate individuals to collect data for the independent and dependent variables, to avoid common response bias. We received complete usable responses from the primary and secondary respondents from 78 companies (a $25 \%$ response rate) who reported on a total of 1572 alliances that had been established at least 2 years earlier. About 12 percent of the alliances studied were terminated as of 1998. The industry breakdown of companies was as follows: Chemicals 19 percent, Pharmaceuticals 17 percent, Electronics 22 percent, Computers (hardware and software) 24 percent, Communications and others 18 percent. Simple $t$-tests revealed that companies in our respondent group were slightly larger in terms of annual sales and employee size than the non-respondent group.

\section{EXPLANATORY VARIABLES}

\section{Alliance experience}

Alliance experience, which has often been used as a proxy for a firm's alliance capability, was measured by taking a count of each firm's alliances over a 10-year period from 1988 to 1997. Our primary source for generating a raw count of each firm's alliances was the Mergers, Acquisitions and Alliances' database of the Securities Data Corporation (SDC), which maintains a complete list of firms' alliances for all years beginning in 1988. To minimize reporting errors, we checked with our primary respondent in each company to determine whether the alliances reported by SDC matched with their internal records. Some companies reported a fairly high discrepancy between their own records and that of SDC. The discrepancies appeared to exist for three primary reasons. First, SDC missed some alliances because companies do not necessarily report all alliances they engage in, either for strategic or tactical reasons. Second, some alliances did not progress following the announcement due to partner disagreements or inertia. Finally, it appeared that some alliances were announced but there was no strong commitment or intent to proceed with the announced alliance (for example, the firm's intent in announcing an alliance was merely to provide a signal to competitors). To the extent possible, we corrected the discrepancy in the published data on alliances for each company in our sample and used the corrected alliance count as a measure of each firm's alliance experience. A straightforward technology licensing deal for a fee is not considered an alliance for our purpose unless it was also accompanied by an agreement to access other skills across some part of the value chain.

\section{Dedicated alliance function}

The primary respondent was asked to indicate whether their company had created a dedicated alliance function (defined as 'a position to manage or coordinate all alliance-related activity in the firm'). Firms with a dedicated alliance function were also asked to provide information on when the alliance function was established, how many people were in the function, and the managerial position of the person who headed the function. ${ }^{2}$

\section{DEPENDENT VARIABLES: ALLIANCE SUCCESS/PERFORMANCE}

We created two sets of measures for a firm's overall alliance success rate during the time period 1993-97. One measure was based on the increase in the firm's stock market value following an alliance announcement (a market-based measure of alliance success) and the other measure based on the assessments of the alliance managers at least 2 years after the alliance began.

\footnotetext{
${ }^{2}$ To the extent possible, we cross-checked this information from public sources such as annual reports and company websites.
} 


\section{Abnormal stock market returns}

The first measure of alliance success was determined on the basis of incremental value creation, measured in terms of abnormal stock market gains following alliance announcements. Several recent studies have relied on this methodology to assess alliance-related performance (Anand and Khanna, 2000; Merchant and Schendel, 2000; Koh and Venkatraman, 1991). To estimate incremental value creation for each firm, we extracted the residuals from a standard asset-pricing model used to predict firms' returns following event announcements. We used daily data on stock market returns for each publicly listed firm in the sample over a 180-day period prior to the event day to estimate the market model (Fama, 1976):

$$
r_{i t}=\alpha_{i}+\beta_{i} r_{m t}+\varepsilon_{i t}
$$

Here $r_{i t}$ represents the daily returns to firm $i$ on day $t, r_{m t}$ denotes the corresponding daily returns on the value-weighted $\mathrm{S} \& \mathrm{P} 500, \alpha_{i}$ and $\beta_{i}$ are firm-specific parameters, and $\varepsilon_{i t}$ is distributed i.i.d. normal. The estimates obtained from this model are then used to predict returns for each firm over a 14-day period surrounding the event day, i.e., event days -10 to $+3^{3}$, as:

$$
R_{i t}=\alpha_{i}+\beta_{i} r_{m t}
$$

where $R_{i t}$ are the predicted daily returns, and $\alpha_{i}$ and $\beta_{i} r_{m t}$ are the model estimates. Thus the daily firm-specific excess returns can be calculated as:

$$
\varepsilon_{i t}=r_{i t}-R_{i t}
$$

where $\varepsilon_{i t}$ are the daily firm-specific excess returns.

The excess returns reflect the daily, unanticipated movements in the stock price for each firm over the event period. The abnormal returns data were used to create two market-based measures of a firm's alliance success: (a) percentage abnormal stock gains for each individual alliance formed by each firm (INDABNORMAL) during 1993-97, and (b) for each firm, an average of the abnormal

\footnotetext{
${ }^{3}$ The selection of this period is consistent with most prior research (Anand and Khanna, 2000) using this methodology to examine alliance value creation. Since some studies also use shorter periods -3 to +3 days, we tested our results for different periods but the results did not substantively change our results or conclusions.
}

stock gains across all its alliances formed during 1993-97 (AVGABNORMAL).

\section{Managerial assessments of long-term alliance success}

Following prior studies (Beamish, 1984; Anderson and Narus, 1990; Tuchi, 1996; Hebert and Beamish, 1997), we used a survey instrument to collect managerial assessments on the performance of every alliance formed by each firm during the 1993-97 time period. The Appendix lists the items that were used to assess alliance performance. Given the multipurpose nature of most alliances, we used a number of survey items to measure alliance success, including: the extent of harmony between alliance partners, the extent to which the parent firm meets its alliance objectives, the extent to which the alliance is seen as enhancing the competitive position of the parent firm, and finally, the extent to which the parent firm acquires critical skills or capabilities from its alliance partner. Respondents used a 7-point Likert type scale to evaluate each alliance in their firm on each of these dimensions (see the Appendix). Individual alliances were evaluated by a manager or executive (secondary respondent) within each firm who was responsible for managing that particular alliance. In each firm, the person providing alliance performance evaluation was different from the primary respondent who provided us data on the firm's alliance function.

The above data were used to create two perceptual measures of long-term alliance success at the firm level. First, for each firm we rated every alliance that received a score of 4 or more on three of the four dimensions of performance as 'successful or satisfactory.' In more than 85 percent of the cases the respondents also rated alliances that were categorized as 'successful' using our methodology, as 'successful' when they responded to item 5 in the Appendix. For each firm, we then aggregated these scores across all its alliances to calculate its overall alliance success rate during 1993-97. This was essentially the ratio of the firm's successful/satisfactory alliances to all its alliances during this time period (SUCRATE). For example, if using the above methodology, 6 of Company's 10 alliances formed during 1993-97 were rated as 'successful,' Company A's success rate is 0.60. Second, for every firm, we also summed up the ratings across the four performance dimensions for 
each of its alliances (PERF) and then created a second measure of firm-level alliance success by taking an average of this score across all its alliances (AVGPERF). These two perceptual measures of firm-level alliance performance (SUCRATE and AVGPERF) correlated very strongly (0.88).

\section{Control variables}

Apart from controlling for alliance experience, we controlled for firm size in our model because larger firms may have more resources to enhance the probability of alliance success. Large firms are also more likely to have more alliance experience because of more opportunities to engage in alliances (thereby influencing the success rate). We also controlled for industry effects using industry dummies. In part of our analysis we also controlled for the type of alliance in question, namely whether it was an equity or nonequity alliance.

\section{DATA ANALYSIS AND RESULTS}

We conducted numerous analyses to test our hypotheses. First, we used ordinary regression analysis to test Hypotheses 1 and 2; i.e., to determine whether a dedicated alliance function was a significant explanatory factor for alliance success (based on both abnormal stock returns and managerial assessments of long-term success). We also separated our sample into two categories - those with an alliance function and those without it - and ran simple $t$-tests to determine whether those firms with a dedicated alliance function realized significantly higher abnormal returns and a higher long-term success rate. The latter analysis also provided a partial test for Hypothesis 3 that examined a possible relationship between a dedicated alliance function and number of alliances (alliance experience). To test Hypothesis 3 we also analyzed an eventhistory model to examine the impact of alliance experience on the hazard of firms' setting up a dedicated alliance function. Given the possible endogeneity and sample selection bias (Shaver, 1998) due to the relationship between alliance experience and the existence of a dedicated alliance function, we also tested Hypotheses 1 and 2 by using Heckman type two-stage models (Heckman, 1979). Finally, we examined both the Pearson correlation between abnormal returns and long-term success and we included the abnormal returns measure as an explanatory variable in a regression equation with long-term alliance success as the dependent variable.

Table 1 provides the descriptive statistics and the correlation matrix for all the key variables.

Alliance experience correlates positively with both the ex ante market-based measure of

Table 1. Descriptive statistics and correlation matrix

\begin{tabular}{lcclcccrr}
\hline & Mean & S. D. & EXP & AVGABNOR & AVG-Wealth & SUCRATE & AVGPERF & Sales \\
\hline EXP & 23.03 & 19.102 & 1.00 & & & & & \\
AVGABNOR & 0.840 & 3.914 & $0.19^{*}$ & 1.00 & & & & \\
AVG-Wealth & 58.32 & 28.052 & 0.17 & $0.35^{* *}$ & 1.00 & & \\
SUCRATE & 0.595 & 0.164 & $0.27^{* *}$ & $0.33^{* *}$ & 0.15 & 1.00 & & \\
AVGPERF & 3.841 & 1.047 & $0.37^{* *}$ & $0.32^{* *}$ & 0.17 & 0.88 & 1.00 & 1.00 \\
Sales & 4449 & 3823 & $0.42^{* *}$ & 0.12 & 0.13 & 0.14 & 0.16 & 1.00 \\
\hline
\end{tabular}

EXP = total alliances formed by each firm during 1988-97

AVGABNOR $=$ average percentage abnormal stock market gains per alliance, for each firm

AVG-Wealth $=$ average wealth generated per alliance, for each firm (\$ million). This measure is created by multiplying percentage abnormal gains with the firm's equity value

SUCRATE = long-term alliance success rate for each firm (percent rated successful)

AVGPERF = long-term alliance performance for each firm, based on average of ratings received by all the firm's alliances on the four performance dimensions in the Appendix

Sales $\quad=$ annual sales in dollars in 1996 for each firm (\$ million)

${ }^{*} p$-value $<0.10 ;{ }^{* *} p$-value $<0.05$

Besides estimating correlations for key variables at the firm level, we also estimated the correlation between abnormal gains following alliance announcement (INDABNORMAL) and managerial assessment of alliance performance (PERF) at the level of each individual alliance, and found it to be 0.43 ( $p$-value $<0.05$ ). 
abnormal stock market gains following alliance announcements and alliance success based on managerial assessments of alliance performance. The correlation matrix also shows that alliance success measured in terms of abnormal stock market gains is positively and significantly correlated with firmlevel alliance success as measured by managerial assessments. This analysis suggests that there is a strong relationship between the market's ex ante evaluation of value creation through alliances and the firm's alliance success based on ex post assessments. In later sections of the paper, we examine and discuss this issue in greater depth. Since the existence of a dedicated alliance function has been measured by a categorical rather than a metric variable, we did not include it in the Pearson Correlation matrix (Hair et al., 1998). However, we found that almost 64 percent of the companies in our sample had established a dedicated alliance function. The average size of this function was roughly 5 people per firm and its average duration was 3.9 years. One-way analysis of variance did not reveal any significant differences in the key variables across industry categories.

Table 2 provides the results of the first set of regression analysis with the firm's average abnormal stock gains per alliance (AVGABNORMAL) as the dependent variable.

Since prior research views alliance experience as a primary driver of alliance capability and success, we treat it as a base case and begin all our analyses by examining the impact of this variable in the first model and then controlling for it in all subsequent models. In Model I, alliance experience is positively related to abnormal stock market response. However, although the sign for experience is positive, it is not significant. Results of Model II show that a dedicated alliance function is significant in explaining abnormal stock market gains. It suggests that the market rewards firms that establish a separate, dedicated mechanism to coordinate their alliances and learn from them. When we include both these explanatory variables together into the analysis in Model III the $R^{2}$ increased significantly from 0.018 to 0.057 . A partial $F$-test comparing Models I and III revealed that adding the alliance function variable after accounting for experience significantly adds to the explanation of the dependent variable $(p<0.10)$. We find that although the dedicated alliance function continues to remain significantly and positively related to the dependent variable, alliance experience is not significant. Overall, this analysis provides moderate support for Hypothesis 1 .

We then replicated the analysis using the abnormal stock gains associated with each individual alliance of a firm as the dependent variable (INDABNORMAL). In this case, Alliance Experience is a count of all the alliances formed by each firm up to, and including, the specific alliance whose abnormal gains are being assessed. This analytical approach is consistent with prior alliance research based on similar event methodology (Anand and Khanna, 2000; Koh and Venkatraman, 1991). Here, we also estimated fixed firm effects using firm

Table 2. Regression analysis examining the relationship between abnormal stock market gains following alliance announcements and both alliance experience and dedicated alliance function

Dependent variable: average percentage abnormal stock market gains per alliance, per firm (AVGABNORMAL)

\begin{tabular}{lcccc}
\hline & Model I & Model II & Model III & Model IV \\
\hline Alliance experience & 0.17 & & 0.15 & 0.13 \\
Alliance function & & $0.181^{*}$ & $0.167^{*}$ & $0.148^{*}$ \\
Annual sales & 0.076 & 0.054 & 0.035 & 0.032 \\
Chemical & & & & 0.07 \\
Pharmaceutical & & & & 0.091 \\
Electronics & & & & -0.07 \\
Computers & 0.018 & 0.045 & 0.057 & 0.026 \\
$R^{2}$ & 1.47 & $1.73^{*}$ & $2.44^{* *}$ & $1.875^{* *}$ \\
$F$-value & 78 & 78 & 78 & 78 \\
No. of observations & & & & \\
\hline
\end{tabular}

$$
{ }^{*} p<0.10 ;{ }^{* *} p<0.05 ;{ }^{* * *} p<0.01
$$


Table 3. Regression analysis examining the relationship between abnormal stock market gains following alliance announcements and both alliance experience and dedicated alliance function

Dependent variable: Percentage abnormal stock market gains per alliance (INDABNORMAL)

\begin{tabular}{|c|c|c|c|c|c|c|}
\hline & Model I & Model II & Model III & Model IV & Model V & Model VI \\
\hline $\begin{array}{l}\text { Cumulative } \\
\text { alliance } \\
\text { experience }\end{array}$ & $0.23^{* *}$ & - & $0.218^{* *}$ & $0.161^{*}$ & $0.229^{* *}$ & $0.141^{*}$ \\
\hline Alliance function & - & $0.328^{* *}$ & $0.346^{* *}$ & $0.273^{* *}$ & $0.362^{* *}$ & $0.206^{*}$ \\
\hline Annual sales & 0.042 & 0.029 & 0.018 & 0.025 & 0.048 & 0.031 \\
\hline $\begin{array}{l}\text { Fixed firm } \\
\text { effects }\end{array}$ & Included & Included & Included & Included & Included & Included \\
\hline Equity alliance & & & & $0.126^{*}$ & & \\
\hline Chemical & & & & 0.033 & 0.038 & 0.042 \\
\hline Pharmaceutical & & & & 0.048 & 0.057 & 0.039 \\
\hline Electronics & & & & 0.062 & 0.061 & 0.067 \\
\hline Computers & & & & 0.015 & 0.021 & 0.017 \\
\hline$R^{2}$ & 0.152 & 0.187 & 0.239 & 0.281 & 0.291 & 0.223 \\
\hline \multirow[t]{2}{*}{$N$} & 1572 & 1572 & 1572 & 1572 & 576 & 996 \\
\hline & Full sample & Full sample & Full sample & Full sample & Equity alliances & Non-equity alliances \\
\hline
\end{tabular}

${ }^{*} p<0.10 ;{ }^{* *} p<0.05 ; * * * p<0.01$

Model V is estimated only for all equity alliances.

Model VI is estimated only for all nonequity alliances.

dummies, to allow for interfirm unobserved heterogeneity in alliance capabilities and success. Several things can be noted from the results presented in Table 3.

In Models I, II, and III we see that even after controlling for fixed firm effects cumulative alliance experience and a dedicated alliance function are both significant explanators of abnormal stock market gains following alliance announcements. The results also suggest that even within the same firm having greater prior alliance experience and having a dedicated unit to manage and coordinate alliances at the time when a particular alliance is formed and announced creates greater value. ${ }^{4}$ In Model IV, when we replicated the analysis by controlling for alliance type (equity vs. nonequity) we found it was marginally significant $(p<0.10)$; however, industry effects were not significant. Collectively, the results of Tables 2 and 3 provide support for Hypothesis 1. We also conducted the above analysis without estimating fixed

\footnotetext{
${ }^{4}$ For firms with an alliance function, we compared their average alliance value creation, before and after the establishment of such a function and found the difference to be significant. This is interesting in light of the fact that average alliance value creation across the sample as a whole exhibited a declining (though insignificant) trend over time.
}

firm effects (this implicitly assumes that after controlling for experience and investment in a dedicated alliance function firms have similar capabilities to manage alliances). Including fixed firm effects improves the $R^{2}$ significantly (by more than 0.10) as compared to not including them. The evidence indicates that there are large differences in the unobserved capabilities of firms in managing alliances. At the same time, after controlling for these differences, prior alliance experience and having a dedicated alliance function appear to significantly increase the value that firms generate from alliances. We then conducted the analysis separately for equity and nonequity alliances (Model V and VI). Interestingly we found that although experience and alliance function were significant in explaining abnormal gains for both equity and nonequity alliances, the impact of these variables was greater for equity alliances. It appears that equity alliances, which are not only more complex in nature but also share some homogeneous characteristics in terms of their governance structures, derive greater benefits from having prior experience as well as having a dedicated alliance function.

In Table 4 we regressed the firm's long-term alliance success based on managerial assessments, on the explanatory variables. 
Table 4. Regression analysis examining relationship between long-term alliance success and both explanatory variables alliance experience and dedicated alliance function

Dependent variable: Models Ia-IVa: Long-term alliance success rate of the firm (SUCRATE) Models Ib-IIb: Long-term average alliance performance (AVGPER)

\begin{tabular}{lcccccc}
\hline & Model Ia & Model IIa & Model IIIa & Model IVa & Model Ib & Model IIb \\
\hline Alliance experience & $0.212^{* *}$ & & $0.134^{*}$ & $0.092^{*}$ & $0.196^{* *}$ & $0.156^{* *}$ \\
Alliance function & & $0.322^{* * *}$ & $0.285^{* * *}$ & $0.288^{* * *}$ & $0.320^{* * *}$ & $0.350^{* * *}$ \\
Annual sales & 0.039 & 0.057 & 0.054 & 0.049 & 0.068 & 0.080 \\
Chemical & & & 0.112 & & 0.068 \\
Pharmaceutical & & & -0.108 & & 0.075 \\
Electrical & & & & 0.063 & $0.123^{*}$ \\
Computers & 0.0385 & 0.0921 & 0.127 & 0.151 & 0.171 & 0.056 \\
$R^{2}$ & $3.951^{* * *}$ & $9.04^{* * *}$ & $6.907^{* * *}$ & $3.93^{* * *}$ & $8.84^{* * *}$ & $4.84^{* * *}$ \\
$F$-value & 78 & 78 & 78 & 78 & 78 \\
No. of observations & 78 & & & & & \\
\hline
\end{tabular}

${ }^{*} p<0.10 ;{ }^{* *} p<0.05 ;{ }^{* * *} p<0.01$ (two-tailed test)

Figures represent standardized beta coefficients.

In Models Ia-IVa the dependent variable is the firm's overall alliance success rate (SUCRATE), whereas in Models Ib and IIb it is the firm's overall alliance performance (AVGPER). The latter is based on an average of the ratings received by each of its alliances across the four performance dimensions mentioned in the Appendix. Results of Models Ia-IVa show that both alliance experience and a dedicated alliance function are significant in explaining the firm's long-term alliance success, both when the explanatory variables are included individually or together in the regression models. Of the two variables, the alliance function has a greater effect in terms of explaining long-term alliance success rates. This result provides strong support for Hypothesis 2. Models Ib and IIb, with the alternate measure of long-term alliance success, yield similar results.

We then investigated whether firms with an alliance function achieved different levels of success compared to those firms without an alliance function (See Table 5A). This analysis shows that firms with a dedicated alliance function have more alliance experience and have a higher success rate on both our measures of success. The relationship between alliance experience and the existence of a dedicated alliance function provides partial support for Hypothesis 3. To examine this further, we also analyzed an event-history model to examine the impact of alliance experience on the hazard or likelihood of firms establishing a dedicated alliance function to manage their large/growing alliance portfolio. Table 5B provides these results.
We find that greater alliance experience increases the likelihood of firms setting up a dedicated alliance function. A risk ratio analysis shows that for one unit increase in experience the likelihood of setting up the alliance function goes up by 18 percent. Overall, this analysis provides support for Hypothesis 3. However, given the nature of our data and analysis here, it is difficult to disentangle the exact causal direction of this relationship. Generally, our fieldwork and discussions with company executives suggest that firms with more alliances seem to be the first to recognize the need to have such a function. Our results also show that firms with a dedicated alliance function achieved abnormal stock market gains of 1.35 percent on average and reported that 63 percent of alliances were successful. On the other hand, firms without an alliance function achieved 0.18 percent stock market gains on average and reported only a 50 percent long-term success rate. We also found that 76 percent of the firms in the top quartile of abnormal stock market gains had an alliance function as compared to only 41 percent in the bottom quartile. Overall, these results provide support for Hypotheses 1 and 2 discussed earlier.

We also examined the relationship between abnormal stock response and the long-term success rate based on managerial evaluations. First, the significant correlation between these two variables in the Correlation Matrix provides evidence of their positive association. Second, we also regressed the firms' long-term alliance success rate not only 
Table 5A. Comparison of firms with and without a dedicated alliance function

\begin{tabular}{lccc}
\hline & $\begin{array}{c}\text { Firms with } \\
\text { dedicated } \\
\text { alliance } \\
\text { function }\end{array}$ & $\begin{array}{c}\text { Firms without } \\
\text { dedicated } \\
\text { alliance } \\
\text { function }\end{array}$ & $t$-value \\
\hline Alliance experience & 29.13 & 13.67 & $2.71^{* *}$ \\
Alliance success rate & $63.29 \%$ & $50.67 \%$ & $5.01^{* * *}$ \\
Avg. alliance perf & 3.89 & 3.12 & $2.88^{* * *}$ \\
Abnormal returns & $1.35 \%$ & $0.18 \%$ & $1.91^{*}$ \\
Avg. wealth created & $\$ 75.14$ million & $\$ 20.24$ million & 1.04 \\
\hline
\end{tabular}

${ }^{*} p<0.10 ;{ }^{* *} p<0.05 ;{ }^{* * *} p<0.01$

Figures in columns indicate mean values for each group.

Table 5B:. Event history model to investigate the hazard of firms setting up a dedicated alliance function given their alliance experience

\begin{tabular}{lc}
\hline Variables & \\
\hline Alliance experience & $0.117^{* *}$ \\
Annual sales & -0.002 \\
Chemical & -0.322 \\
Pharmaceutical & -0.452 \\
Electronics & -0.004 \\
Computers & -0.798 \\
Chi-square & $18.972^{* * *}$ \\
$N$ & 78 \\
\hline & \\
** $p<0.05 ;{ }^{* * *} p<0.01$ \\
The risk ratio $\left(e^{\beta}\right)$ for Experience is \\
1.185. This suggests that one unit increase \\
in alliance experience increases the haz- \\
ard of setting up a dedicated alliance \\
function by almost 18\%.
\end{tabular}

on the earlier explanatory variables but also on percentage abnormal stock market gains as an additional explanatory variable. We observed that although the existence of a dedicated alliance function continues to remain significant in explaining long-term alliance success, the variable for abnormal gains is also significant. We also investigated whether the relationship between the market and perceptual measures of alliance performance varied, depending upon whether a particular alliance was rated 'successful' or 'unsuccessful' based on managerial assessments. We found that 75 percent of the alliances rated 'successful' ex post by the managers also had positive, ex ante abnormal gains for the firm. However, in the case of alliances rated 'unsuccessful' ex post, only 42 percent had positive ex ante stock gains. Thus, our results offer support for the efficient markets argument (though there is still considerable unexplained variance).

We further examined whether the regression analysis presented thus far suffered from selfselection bias and endogeneity (Shaver, 1998; Zajac and Westphal, 1996), and if so, to correct for it using Heckman type selection models (Heckman, 1979). Firms choose strategies based on their attributes; therefore strategic choice can be endogenous and self-selected and empirical models that fail to account for it can potentially be misspecified and their conclusions inaccurate. In our case, we could view establishment of a dedicated alliance function as a strategic decision. As suggested earlier, there might be some endogeneity between alliance experience and having an alliance function such that firms with more experience may be more likely to have such a function. If firms are self-selecting themselves with respect to creating a dedicated alliance function based on their alliance experience and on some other unobservable attributes, then self-selection will likely bias the estimates of the strategy choice variable, i.e., the alliance function variable. Heckman models basically estimate two equations. The first equation is a probit model that predicts whether or not the strategic choice variable is observed. The second equation is a regular regression model that regresses the dependent variable (alliance success) on given explanatory variables (alliance experience, alliance function, firm size, industry effects, etc.) as well as an additional parameter (lambda) that estimates the impact of self-selection, if any. The selfselection parameter, lambda, is estimated on the basis of the first equation. Table 6 provides the results. 
Table 6. Regression analysis based on Heckman type model

Dependent variable: Models I and III-Alliance success rate

Models II and IV-Average abnormal gains per alliance

\begin{tabular}{lcccc}
\hline & Model I & Model II & Model III & Model IV \\
\hline Alliance experience & 0.0830 & 0.0310 & 0.091 & 0.059 \\
Alliance function & $0.3103^{* * *}$ & $0.3901^{* *}$ & & \\
Firm sales & 0.0206 & 0.0494 & 0.031 & 0.052 \\
Chemical & 0.0553 & 0.0638 & 0.063 & 0.071 \\
Pharmaceutical & 0.0728 & 0.0713 & 0.072 & 0.075 \\
Electronics & $-0.0991^{*}$ & $-0.1219^{*}$ & $-0.107^{*}$ & $-0.138^{*}$ \\
Communications & -0.0382 & -0.0703 & -0.048 & -0.084 \\
Lambda & $-0.3072^{*}$ & $-0.2385^{*}$ & $-0.251^{*}$ & -0.187 \\
$R^{2}$ & 0.2517 & 0.0541 & 0.158 & 0.039 \\
$F$-value & 3.45 & 2.19 & 2.24 & 1.58 \\
$N$ & 78 & 78 & 49 & 49 \\
\hline
\end{tabular}

${ }^{* *} p$-value $<0.05 ;{ }^{* * *} p$-value. $<0.01$

The Probit model estimated before the regression models described above showed that greater alliance experience was positively and significantly linked $(p<0.01)$ to the probability of firms having a dedicated alliance function to manage their alliance activity.

The initial probit analysis revealed that firms with more alliance experience have a significantly greater probability $(p<0.05)$ of having a dedicated alliance function. The regression analysis in Model I and Model II shows that independent of the self-selection process a dedicated alliance function is positively and significantly related to different measures of alliance success. The significance of the experience variable either diminishes or disappears in these models. We also note that the self-selection parameter lambda is just about significant $(p<0.10)$. It implies that observable and unobservable firm characteristics that impact self-selection also have an impact on the firm's alliance success.

We also conducted this analysis only for those firms that had an alliance function. The results are presented in Models III and IV. Once again, we note that the self-selection parameter is significantly linked to alliance success. It means that alliance success for firms with an alliance function is greater than alliance success for all firms with equivalent observable characteristics had they chosen to have such a function. In other words, unobservable characteristics that affect the choice of creating such a function may also impact alliance success. In these models, we once again note that alliance experience, after accounting for selfselection, does not have a significant relationship with alliance success; rather the effects on alliance success may be through the choice of having an alliance function.
Finally, we conducted other robustness checks of our analysis. First, we found that the results for the abnormal gains' analysis were not sensitive to the particular event window used. Using a smaller 3- or 5-day window surrounding the event day to compute the abnormal gains does not change the results. Moreover, using a measure of total wealth created instead of abnormal percentage gains also yields similar results. Second, in some cases a firm may announce two or more alliances within the event window for one particular alliance. A check of our data revealed that this happened in less than 3 percent of alliances in our sample. Deleting these apparently 'noisy' alliances did not change our results substantively. Third, we also examined the sensitivity of our results to our alliance success measure based on managerial assessments. We considered only those alliances that got a score of 5 or more (instead of 4 or more) as 'successful' to estimate a firm's overall alliance success rate. Although the average success rate for the sample dropped down to 51 percent using this approach, the results for the importance of experience and dedicated alliance function did not change. Fourth, instead of taking an average of the performance assessments across all alliances of each respective firm as the dependent variable, we used the performance assessment of each of the individual alliances of a firm as the dependent variable and conducted the analysis by controlling for fixed firm effects. Investment in a dedicated alliance function 
continued to be a significant explanator of alliance success.

\section{DISCUSSION}

Our analyses indicate that when a firm makes an investment in a dedicated alliance function designed to capture and apply the know-how from its alliance experience, the firm's alliance success rate increases. We find that a firm's investment in a dedicated alliance function is a more significant predictor of the firm's overall alliance success than a firm's alliance experience. The results suggest that firms that invest in a capability at managing alliances are able to enhance the probability of success - both in the short run (generating a positive stock response) and in the long run (meeting the alliance objectives). Our initial analyses also suggest that, consistent with previous studies, alliance experience is positively associated with a firm's overall alliance success, especially long-term success based on managerial assessments.

However, our findings were modified in some important ways when we replicated the analysis using Heckman models. First, they validate one of the main results observed in the regular regression analysis, namely that a dedicated alliance function enhances a firm's alliance success and value creation through alliances, independent of self-selection. Second, they indicate that some of the unobservable characteristics that impact self-selection have an impact on the firm's alliance success rate. Perhaps some of these unobservable characteristics relate to some firms being more learning and coordination oriented than other firms, which in turn influences their alliance success rates. Third and more importantly, they show that if we account for self-selection, the role of alliance experience in directly impacting alliance success diminishes. This latter result is, in fact, contrary to some of the findings of our own earlier analysis that fails to account for such endogeneity. This result also has important implications for prior research that has focused on alliance experience as an important explanator of alliance capability and success. Our results show that although alliance experience is important, its impact seems to work through the creation of a dedicated structure to coordinate and leverage that experience more effectively.
Our findings also suggest that alliances do create significant increases in market value (wealth) for firms. Indeed, firms with a dedicated alliance function entered into an average of 29 alliances during the 1993-97 time period and collectively these alliances generated a substantially large increase in market value of for these firms. The positive relationship between the firm's abnormal stock gains following alliance announcements and its alliance function may be a signal of the market's confidence in the probability of long-term alliance success, due to the firm's investment in the alliance function. It is possible that the creation of a dedicated alliance function sends a signal to the marketplace and to potential partners that the company is committed both to its alliances and to managing them effectively. Thus, the market may respond more positively to future alliance announcements based on the assumption that the firm has been able to improve its ability to identify good alliance opportunities and generate value from them. However, it is also very likely that in many cases the market may not even really be aware of the explicit existence of this function. However, having such a function can improve firms' alliance abilities so as to be able to identify appropriate alliance partners, screen alliance partners more effectively, attract alliance partners that are stronger and more compatible, and eventually present and position the alliance more appropriately to the external world of customers, competitors, and, of course, investors. The abnormal gains are primarily a reflection of the market rewarding all of the above, even though investors or stock analysts may not be directly aware of the existence of a dedicated alliance function that lies behind the firm's actions.

As discussed earlier, we found that a dedicated alliance function plays an important knowledge management role and provides a vehicle for sharing best practices. We believe this is an important reason for the increased long-term success rate. Through our interviews we learned that most alliance functions were attempting to capture and codify knowledge to more effectively manage each phase of the alliance life cycle. Most interviewees indicated that they were developing tools to more effectively manage the following five key phases of the alliance life cycle: (1) making the alliance business case, (2) partner assessment and selection, (3) alliance negotiation and governance, (4) alliance management, and (5) alliance assessment and termination (see Figure 1 for an 


$\begin{array}{lllll}\text { ALLIANCE } & \text { PARTNER } & \text { ALLIANCE } & \text { ALLIANCE } & \text { ALLIANCE } \\ \text { PLANNING } & \text { SELECTION } & \text { NEGOTIATION } & \text { MANAGEMENT } & \text { TERMINATION } \\ * \text { Value Chain } & * \text { Partner } & * \text { Negotiations Matrix. } & * \text { Trust-building } & * \text { Relationship } \\ \text { Analysis } & \text { Screening Form } & * \text { Needs v/s } & \text { worksheet } & \text { Evaluation } \\ \text { Form } & * \text { Cultural Fit } & \text { Wants Checklist } & * \text { Alliance } & \text { Form } \\ * \text { Needs Analysis } & \text { Evaluation } & * \text { Alliance Contract } & \text { Communication } & * \text { Yearly Status } \\ \text { Checklist } & \text { Form } & \text { Template } & \text { Infrastructure } & \text { Report } \\ & & * \text { Alliance Metrics } & & * \text { Termination } \\ & & \text { Framework } & & \text { Checklist }\end{array}$

Figure 1. Illustrative example of some codified alliance management tools created by the alliance function

illustrative example of the types of codified tools that the alliance function of one of the companies in our study had created). A common theme of these interviews was that first-hand experience, and systematically learning from that experience, is extremely valuable and does influence a firm's ability to avoid the pitfalls of alliances. This may explain why firms that had invested in a dedicated alliance function had fewer alliances that ended up in outright failure. Stated one executive:

\section{One thing that we've learned is that experience [with alliances] counts. We need people that know what they are doing. But so does our partner. So one thing we look for in our screening process is whether or not the other company is experienced with alliances. That makes a big difference.}

The mere fact that this executive recognized a key partner trait that might influence success suggests that his firm was engaged in an ongoing process of drawing on past experience to enhance the probability of future success. At Hewlett Packard, where we conducted extensive fieldwork, the explicit objective of the alliance function was 'to make alliance management a core competency for HP by leveraging and sharing alliance know-how and best practices across multiple divisions/groups/alliances' (Internal HP document). Given this objective, HP engaged a variety of specific practices to codify, share, and disseminate the alliance know-how accumulated through prior experience.

Our research shows a reasonably high correlation between the stock market's initial response to an alliance announcement and the alliance's long-term success. One interpretation of this result is that the market is actually quite efficient and that studies that use the event study methodology are justified in doing so. If one accepts this interpretation, these two measures are simply correlates of success without any causal relationship (which is the position we adopt in this paper). Of course, it is also possible that alliance announcements that produce a large positive stock market response also generate greater commitment on the part of the firms to ensure that the alliance is successful. In some interviews we asked alliance managers whether they were aware of the stock market response when the alliance was announced. They were generally unaware of the stock market response, except in rare cases where the response was particularly good (or bad). It was difficult to ascertain whether the initial response influenced the firm's (or individual manager's) commitment to the alliance, thereby influencing its long-term success.

Although our research shows that a dedicated alliance function can create value for firms, having such a function may not come without challenges and risks. First and foremost, creating such a function requires a serious investment in manpower and resources. Companies may need to be large enough, or enter into enough number of alliances, to justify and cover those costs. Furthermore, deciding where to locate the function in the organization and more importantly to get line managers to appreciate the role of such a function and recognize its value can be difficult. Finally, establishing codified and consistent processes risks overemphasizing 'process' over 'speed' in decision making. Although this research does not provide empirical analysis pertaining to some of the costs and risks mentioned above, future research may enrich our understanding of the conditions under which the alliance function adds value.

\section{LIMITATIONS AND FUTURE RESEARCH}

In our empirical work, we have only established that an alliance function is linked to better alliance 
success. However, this function may be organized in different ways across companies such that it might lead to some differences in the success and benefits that it provides. A study by Booz Allen \& Hamilton (Harbison and Pekar, 1998) reports that a third of the companies they studied organized the alliance function at the corporate level and a quarter at the business unit level. The rest of the firms had it simultaneously across both levels. Collecting detailed data on the various structural options associated with the alliance function and its relationship with the firm's alliance success will be a useful direction to pursue in future research. In this study we conducted some preliminary analysis by asking companies in our sample where they had located their alliance function-at the corporate level, business unit level, or both. It reveals that although firms with an alliance function located at the corporate level exhibited higher alliance success rate $(66 \%)$ than those that had it at the business unit level (62\%), the difference in alliance success was not statistically significant. Perhaps more fine-grained information about the location of the function and its other characteristics may reveal more interesting findings.

Secondly, even within the same company, the function and its characteristics may not remain static but instead evolve over time. For example, in some companies, managers in the Business Development function were initially assigned this responsibility in addition to their regular business development tasks. Only later did these companies create a separate and dedicated alliance function. The roles and responsibilities of the alliance function may also change gradually over time. In one large company we studied, we found that initially the alliance team was mainly involved in activities such as: (1) helping analyze the basic 'business case' for the proposed alliance, (2) providing assistance in partner assessment and selection, and (3) providing advice in alliance negotiation and contract preparation. In later years, its role changed such that it focused more on ensuring timely and quick escalation of potential alliance conflicts through the company's hierarchy, facilitating joint reviews with alliance partners and, most importantly, learning and sharing the company's best practices on alliance management. Although our current analyses do not capture these evolutionary aspects regarding the alliance function and its role, it may be important to account for it in future research.
We have also suggested that one of the most important benefits of having an alliance function is the ability to learn systematically from prior alliance experience and codify and leverage that learning for future reuse within the company. An important limitation of the study reported here is that we do not have large sample data on the specifics regarding the learning, codification, and sharing efforts. Having such data would not only help us examine their direct impact on firms' alliance capability and success but also understand the influence of the alliance function after controlling for the learning processes. We would expect the alliance function to retain its significance given the other important role it plays besides learning. Future research might investigate this question in greater depth. It would be equally interesting to examine whether the drivers of alliance capability such as alliance experience, alliance function, etc. vary in importance based on the type of alliance in question. We have reported that there are some differences in the importance of these factors across equity and nonequity alliances. In future research it may be useful to examine variance, if any, in their importance across different alliance types (e.g., R\&D, manufacturing, or marketing alliance). Finally, in this research we have also relied on firm-level measures of alliance performance and success in some of our analyses. We recognize this as an important limitation in some respects, since we know from prior research that important transaction-level attributes such as governance structures (Kogut, 1989), information asymmetries (Reuer and Koza, 2000), level of interpartner trust (Kale et al., 2000), etc. also have an impact on eventual alliance success.

\section{CONCLUSION}

In this paper we addressed two questions: (1) do firms that make greater investments in building an alliance capability enjoy greater alliance success as measured by both (a) stock response to alliance announcements and (b) managerial assessments of alliance performance; and (2) does the stock market do a good job of predicting which alliances will, over the long term, be successful at creating value for the participating firms? We found that firms with greater alliance experience and, more importantly, those that invest in a dedicated alliance function have higher success rates. Thus, 
one way to build an alliance capability may be to create a dedicated alliance function. We also found evidence of a positive correlation between stock market response to an alliance announcement and the alliance's long-term performance. We believe this to be one of the first studies to specifically examine this relationship for a key strategic event such as an alliance. Our findings offer support for using the event study methodology in analyzing alliance performance.

In this paper we have only highlighted the importance of having a dedicated alliance function. Yet we have suggested that the value of the alliance function may actually lie in the specific learning and coordination activities that it performs and in the future it may be valuable to probe deeper into the direct impact of those factors on alliance success. We also recognize that, apart from the benefits stated, setting up an alliance function may involve some costs and risks. Finally, we believe that this research on alliance capabilities not only provides insights within the alliance context, but also provides general insights into capability building in other contexts where firms have the potential to build capabilities by proactively learning from their repetitive experiences of specific events or situations.

\section{ACKNOWLEDGEMENTS}

Earlier versions of this paper have been presented at the Emerging Technologies Research Program Annual Conference at the University of Pennsylvania and the Annual Strategy Conference, Winter 2000, at the Marriott School, BYU, Utah. We acknowledge the valuable comments and inputs received from various individuals during these presentations. We are also grateful to the Huntsman Center for Global Competition for their invaluable financial support to this project.

\section{REFERENCES}

Allen J. 1998. Capital markets and corporate structure: the equity carve-outs of Thermo Electron. Journal of Financial Economics 48(1): 99-124.

Alliance Analyst. 1996. Managing alliances-skills for the modern era. March 1998. NewCap Communications: Philadelphia, PA.

Alliance Analyst. 1998. Measuring alliance performance. August 1998. NewCap Communications: Philadelphia, PA.
Anand B, Khanna T. 2000. Do firms learn to create value? The case of alliances. Strategic Management Journal 21(3): 295-316.

Anderson E. 1990. Two firms, one frontier: on assessing joint venture performance. Sloan Management Review 31(2): 19-30.

Anderson E, Weitz B. 1989. Determinants of continuity in conventional industrial channel dyads. Marketing Science 8(4): 301-323.

Anderson J, Narus J. 1990. A model of the distributor's perspective of distributor-manufacturer working partnerships. Journal of Marketing 54: 42-58.

Arino A, de la Torre J. 1998. Learning from failure: towards an evolutionary model of collaborative ventures. Organization Science 9(3): 306-325.

Baldwin C, Forsyth J. 1992. Thermo Electron Corporation. Harvard Business School Case 9-292-104.

Barney J. 1991. Firm resources and sustained competitive advantage. Journal of Management 17(1): 99-120.

Beamish PW. 1984. Joint venture performance in developing countries. Doctoral dissertation, University of Western Ontario, London.

Bleeke J, Ernst D (eds). 1993. Collaborating to Compete. John Wiley: New York.

Chan S, Kensinger J, Keown A, Martin J. 1997. Do strategic alliances create value? Journal of Financial Economics 46: 199-221.

Child J, Yan Y. 1999. Predicting the performance of international joint ventures: an investigation in China. Working paper, University of Cambridge, UK.

Clark K, Fujimoto T. 1990. The power of product integrity. Harvard Business Review 68(6): 107-118.

Conner K, Prahalad C. 1996. A resource-based theory of the firm: knowledge versus opportunism. Organization Science 7(5): 477-501.

Culpan R, Eugene KA. 1993. Cross-national corporate partnerships: trends in alliance formation. In Multinational Strategic Alliances, Culpan R (ed.). Hayworth Press: New York.

Das T, Teng B. 2000. Instabilities of strategic alliances: an internal tensions perspective. Organization Science 11: $77-101$.

Doz Y, Hamel G. 1998.. Alliance Advantage. Harvard Business School Press: Boston, MA.

Dyer JH. 1996. Specialized supplier networks as a source of competitive advantage: evidence from the auto industry. Strategic Management Journal 7(4): 271-291.

Dyer JH, Singh H. 1998. The relational view: cooperative strategy and sources of interorganizational competitive advantage. Academy of Management Review 23(4): 660-679.

Dyer JH, Nobeoka K. 2000. Creating and managing a high performance knowledge-sharing network: the Toyota case. Strategic Management Journal 21(3): 345-368.

Fama E. 1976. Foundations of Finance. Basic Books: New York.

Fiol CM, Lyles MA. 1985. Organizational learning. Academy of Management Review 10(4): 803-813. 
Geringer M, Hebert L. 1991. Measuring performance in international joint ventures. Journal of International Business Studies 22: 249-263.

Grant R. 1996. Toward a knowledge-based view of the firm. Strategic Management Journal, Winter Special Issue 17: 109-122.

Gulati R. 1995. Does familiarity breed trust? The implications of repeated ties for contractual choice in alliances. Academy of Management Journal 38: 85-112.

Gulati R. 1998. Alliances and networks. Strategic Management Journal, Special Issue 19(4): 293-318.

Hair J, Anderson R, Tatham R, Black W. 1998. Multivariate Data Analysis. Macmillan: New York.

Harbison J, Pekar P. 1998. Smart Alliances: A Practical Guide to Repeatable Success. Jossey-Bass: San Francisco, CA.

Harrigan K. 1985. Managing for Joint Venture Success. Praeger: New York.

Hebert L, Beamish P. 1997. Characteristics of Canadabased international joint ventures. In Cooperative Strategies, Beamish P, Killing P (eds). Lexington: Lexington, MA; 254-273.

Heckman J. 1979. Sample selection bias as a specification error. Econometrica 47(1): 153-161.

Henderson R, Cockburn I. 1994. Measuring competence? Exploring firm effects in pharmaceutical research. Strategic Management Journal, Winter Special Issue 15: $61-83$.

Hennart J. 1988. A transaction costs theory of equity joint ventures. Strategic Management Journal 9(4): 361-374.

Kale P, Singh H. 1999. Alliance capability and success. Best Paper Proceedings, Academy of Management Meetings. Chicago, IL.

Kale P, Singh H, Perlmutter H. 2000. Learning and protection of proprietary assets in strategic alliances: building relational capital. Strategic Management Journal 21(3): 217-237.

Kogut B. 1989. The stability of joint ventures: reciprocity and competitive rivalry. Journal of Industrial Economics 38: 183-198.

Kogut B, Zander U. 1992. Knowledge of the firm, combinative capabilities and the replication of technology. Organization Science 3: 383-397.

Kogut B, Zander U. 1995. Knowledge, market failure and the multinational enterprise: a reply. Journal of International Business Studies 26(2): 417-422.

Koh J, Venkatraman N. 1991. Joint venture formations and stock market reactions: an assessment in the information technology sector. Academy of Management Journal 34: 869-892.

McConnell J, Nantel T. 1985. Corporate combinations and common stock returns: the case of joint ventures. Journal of Finance 40(2): 519-536.

Merchant H, Schendel D. 2000. How do international joint ventures create shareholder value? Strategic Management Journal 21(7): 723-738.

Mitchell W. 2000. Alliances: achieving long-term value and short-term goals. Financial Times Mastering Strategy Series: The Complete MBA Companion in Strategy. Pearson Education: London; pp 351-356.
Mitchell W, Singh K. 1996. Survival of businesses using collaborative relationships to commercialize complex goods. Strategic Management Journal 17(3): 169-196.

Mohr J, Spekman R. 1994. Characteristics of partnership success: partnership attributes, communication behavior, and conflict resolution techniques. Strategic Management Journal 15(2): 135-152.

Nelson R, Winter S. 1982. An Evolutionary Theory of Economic Change. Belknap Press: Cambridge, MA.

Parkhe A. 1993. Strategic alliance structuring: a game theoretic and transaction cost examination of interfirm cooperation. Academy of Management Journal 36(4): 794-829.

Pisano G. 1994. Knowledge, integration, and the locus of learning: an empirical analysis of process development. Strategic Management Journal 15(3): 85-101.

Reuer J. 2000. Collaborative strategy: the logic of alliances. Financial Times Mastering Strategy Series-The Complete MBA Companion in Strategy. Pearson Education: London; 346-350.

Reuer J, Koza MP. 2000. Asymmetric information and joint venture performance: theory and evidence for domestic and international joint ventures. Strategic Management Journal 21(1): 81-88.

Saxton T. 1997. The effects of partner and relationship characteristics on alliance outcomes. Academy of Management Journal 40(2): 443-461.

Shaver M. 1998. Accounting for endogeneity when assessing strategy performance. Management Science 44(4): $571-585$.

Simonin B. 1997. The importance of collaborative knowhow: an empirical test of the learning organization. Academy of Management Journal 40(5): 1150-1174.

Smith D, Alexander R. 1988. Fumbling the Future: How Xerox Invented, then Ignored, the First Personal Computer. William Morrow: New York.

Teece DJ, Pisano G, Shuen A. 1997. Dynamic capabilities and strategic management. Strategic Management Journal 18(7): 509-533.

Tuchi C. 1996. Firm heterogeneity and performance of strategic alliances. Working paper, Sloan School of Management.

Wernerfelt B. 1984. A resource-based view of the firm. Strategic Management Journal 5(2): 171-180.

Williamson OE. 1985. The Economic Institutions of Capitalism: Firms, Markets, Relational Contracting. Free Press: New York.

Zajac EJ, Olsen CP. 1993. From transaction cost to transactional value analysis: implications for the study of interorganizational strategies. Journal of Management Studies 30(1): 131-145.

Zajac E, Westphal J. 1996. Who shall succeed? How $\mathrm{CEO} /$ board preferences and power affect the choice of new CEOs. Academy of Management Journal 39(1): 64-72.

Zander U, Kogut B. 1995. Knowledge and the speed of the transfer and imitation of organizational capabilities: an empirical text. Organization Science 6(1): 76-92. 
Zollo M. 1998. Knowledge codification, process routinization and the creation of organizational capabilities. Doctoral dissertation. University of Pennsylvania.

\section{APPENDIX: LIST OF ITEMS USED TO ASSESS ALLIANCE PERFORMANCE}

1. The following items were used to assess the performance of an individual alliance within each company.
2. The alliance was assessed by the manager/individual who was responsible for managing the alliance, or was associated closely with it. These individuals have been referred to as secondary respondents.

3. Respondents used a 7-point Likert type scale to give their assessment on items 1-4 and item 6 , such that " $1=$ Strongly Disagree" and $" 7=$ Strongly Agree".

\begin{tabular}{cll}
\hline $\begin{array}{c}\text { Item } \\
\text { no. }\end{array}$ & \multicolumn{1}{c}{$\begin{array}{c}\text { Items for assessing the } \\
\text { performance of each alliance }\end{array}$} & Theoretical Reference \\
\hline 1. & $\begin{array}{l}\text { The alliance is characterized by a strong and } \\
\text { harmonious relationship between the alliance } \\
\text { partners } \\
\text { The company has achieved its primary } \\
\text { objective(s) in forming this alliance }\end{array}$ & $\begin{array}{c}\text { Anderson (1990); Geringer \& } \\
\text { Hebert (1991); Saxton (1997); } \\
\text { Child \& Yan (1999) }\end{array}$ \\
2. & $\begin{array}{l}\text { The company's competitive position has been } \\
\text { greatly enhanced due to the alliance }\end{array}$ \\
The company has been successful in learning \\
some critical skill(s) or capabilities from its \\
alliance partner(s)
\end{tabular}

